\title{
Treatment Patterns in Danish Patients with Atopic Dermatitis Before and After Hospital Referral
}

\author{
Alexander Egeberg $\cdot$ Jacob P. Thyssen $\cdot$ Jashin J. Wu $\cdot$ Evangeline Pierce $\cdot$ \\ Jorge A. Ross Terres
}

Received: December 11, 2020 / Accepted: January 19, 2021 / Published online: February 6, 2021

(C) The Author(s) 2021

\section{ABSTRACT}

Introduction: A number of treatments for atopic dermatitis $(\mathrm{AD})$ are available; however, longterm treatment patterns and healthcare consumption in patients with $\mathrm{AD}$ are poorly described.

Methods: We conducted a registry-based longitudinal drug utilization study among Danish patients with $\mathrm{AD}$ that were referred to their firstever visit at hospital-based dermatology clinics. Their first visit was in the period between 1 January 2005 and 31 December 2012, and patients were followed up to 5 years after their first visit.

Results: In total, 8213 people with a first-time hospital dermatologist contact for $\mathrm{AD}$ were included in the study (3514 aged 0-9 years, 1501 aged $10-19$ years, 3198 aged 20 years or older). At first visit, a baseline history of moderately potent topical corticosteroid (TCS) use was seen among $46.6 \%$ of children (0-9 years), whereas potent or very potent TCS use was

\footnotetext{
A. Egeberg $(\bowtie) \cdot J$. P. Thyssen

Department of Dermatology, Bispebjerg Hospital, University of Copenhagen, Copenhagen, Denmark e-mail: alexander.egeberg@gmail.com

J. J. Wu

Dermatology Research and Education Foundation, Irvine, CA, USA

E. Pierce · J. A. R. Terres

Eli Lilly and Company, Indianapolis, IN, USA
}

more frequently among older individuals (e.g., $51.1 \%$ and $25.6 \%$ of people aged 50 years or older had used potent and very potent TCS, respectively). The median (interquartile range) annual number of visits to general practitioners was 4 (2-7) for children and 5 (2-8) for adults, in the 12 months prior to referral. Three years after referral, these numbers had decreased to 2 (1-4) and 3 (1-6), respectively. In the first year after referral, $6 \%$ of patients were prescribed systemic corticosteroids, whereas other systemic therapies were used in $5 \%$ or less.

Conclusions: After referral, low proportions of patients received systemic treatment, or potent TCS. These findings highlight considerable differences in treatment patterns between general practitioners and private practice dermatologists, compared with hospital-based dermatologists, and emphasize the need for better adherence to evidence-based treatment guidelines.

Keywords: Atopic dermatitis; Atopic eczema; Registry; Treatment patterns 


\section{Key Summary Points}

\section{Why carry out this study?}

A number of treatments for atopic dermatitis (AD) are available; however, long-term treatment patterns and healthcare consumption in patients with $\mathrm{AD}$ are poorly described.

Using nationwide register-data from Denmark, we assessed the use of different treatment patterns and healthcare consumption, before and after referral to specialized hospital-based dermatology clinics, among children and adults with $\mathrm{AD}$ in a population-based setting.

\section{What was learned from the study?}

Among topical therapies, the most frequently used treatment modalities when presenting to the hospital were potent and moderately potent TCS. Notably, use of topical antibiotics (alone or in combination with TCS) increased in the last 3-6 months prior to the hospital visit, and decreased thereafter, and use of systemic corticosteroids increased dramatically in the months preceding the initial hospital visit.

These findings highlight considerable differences in treatment patterns between general practitioners and private practice dermatologists, compared with hospitalbased dermatologists, and emphasize the need for better adherence to evidencebased treatment guidelines.

\section{DIGITAL FEATURES}

This article is published with digital features, including a summary slide, to facilitate understanding of the article. To view digital features for this article go to https://doi.org/10.6084/ m9.figshare.13604243.

\section{INTRODUCTION}

Atopic dermatitis (AD) is an inflammatory skin disease that is characterized by xerosis and intense pruritus [1], and represents a growing burden to healthcare systems worldwide $[2,3]$, and may considerably impair patients' quality of life [4]. Over the past 30 years, its lifetime prevalence has increased rapidly, namely in the industrialized world, where it has now plateaued at $10-20 \%$ [5]. While AD typically begins early in life, it may be present in all ages, and the disease course is often waxing and waning, and may be accompanied by respiratory allergy and recurrent skin infections [6-8]. The majority of patients (approximately 80\%) have mild disease [9], but a positive family history, early allergen sensitizations, disease onset before 2 years of age, and severe AD early in life appear to be risk factors for more persistent and severe disease in adulthood [10]. The current standard of care includes education and the use emollients, pharmaceutical interventions (topical and systemic treatments), as well as phototherapy. Topical corticosteroids (TCS) are the mainstay of $\mathrm{AD}$ therapy, and even in more severe cases when systemic treatment is needed, TCS are often used in conjunction.

Although many guidelines exist, either local or international, data on real-life treatment patterns over time are lacking. Using nationwide register-data from Denmark, we assessed the use of different treatment patterns and healthcare consumption, before and after referral to specialized hospital-based dermatology clinics, among children and adults with $\mathrm{AD}$ in a population-based setting.

\section{Treatment and Referral Patterns in Denmark}

As a result of the tax-supported healthcare system in Denmark, all residents have equal and unencumbered access to general practitioners, private practicing specialists, and hospital-based treatment without charge. Upon displaying initial symptoms, patients may consult their general practitioner that may initiate treatment or refer patients to specialists. In the majority of 
cases, referrals are sent to private practice dermatologists, but referrals may also be sent directly to hospital-based clinics if deemed appropriate by the general practitioner, or by internal referral, e.g., by a pulmonologist if the patient is already seen in a hospital setting because of asthma. Private practice dermatologists may initiate treatments with topical or systemic treatments (but not biologics as these are reserved for hospital-based clinics) or phototherapy, or may choose to refer patients to a hospital-based dermatology clinic. Data suggest that less than $3 \%$ of patients with $\mathrm{AD}$ seen in private practice are treated with systemic therapies, including cyclosporine, methotrexate, and azathioprine [11]. While cyclosporine is a key medication of conventional AD treatment in many countries, and widely recommended in international guidelines, historically it is very rarely used for AD in Denmark [12, 13].

According to national Danish guidelines [14], treatment of $\mathrm{AD}$ should be done in a stepwise approach, using emollients as baseline therapy. Recommendations are that mild-tomoderate $\mathrm{AD}$ is treated with low potency (e.g., hydrocortisone) or moderately potent (e.g., hydrocortisone-17-butyrate) TCS or topical calcineurin inhibitors (TCI). Crisaborole is not marketed in Denmark and thus not recommended. For moderate-to-severe AD, recommendations are treatment with potent (e.g., betamethasone) TCS or TCI, and systemic treatment should be reserved for severe treatment refractory AD cases. Phototherapy is used for mild-to-moderate AD in adults, but only for moderate-to-severe AD in children. Very potent (e.g., clobetasol propionate) TCS are generally not recommended for patients with $\mathrm{AD}$ in Denmark. Importantly, systemic corticosteroids are not recommended for treatment of $\mathrm{AD}$ in Denmark as standard of care, but may be considered for acute and severe flares in special circumstances. During the current study period, dupilumab was not marketed in Denmark.

\section{METHODS}

\section{Data Sources}

Denmark has a long tradition of registry-based research due to the availability of nationwide administrative and healthcare registry data [15]. At birth or migration, all Danish residents are assigned a unique, permanent, and unambiguous ten-digit personal identification number that is used across a myriad of registries and databases to enable cross-linkage at individual level. This number serves as the foundation for the Civil Registration System [16], which contains information such as date of birth, sex, migration, and date of death. All inpatient and outpatient hospital diagnoses are recorded according to the Tenth Revision of the International Classification of Diseases (ICD-10) in the National Patient Registry [17]. Hospitalbased use of systemic drugs, biologics, and phototherapy treatments (during admission or from outpatient hospital clinics) is also recorded in this registry as treatment procedure codes. Treatments in primary (e.g., general practitioners) and secondary care (e.g., private dermatologists), e.g., phototherapy at private dermatologists, are recorded in the Health Care Statistics Registry [18]. The Danish National Prescription Registry contains complete information from 1 January 1995 and onwards on all prescriptions dispensed to Danish residents at community pharmacies [19]. Registered drugs are categorized according to the Anatomical Therapeutic Chemical classification, a hierarchical classification developed by the World Health Organization for purposes of drug use statistics.

\section{Ethical Approval}

Approval from an ethics committee is not required for register studies in Denmark (Danish law: Lov om videnskabsetisk behandling af sundhedsvidenskabelige forskningsprojekter, § 14, stk. 2). 


\section{Statistical Analyses}

We obtained treatment data for all patients, aged 0-100 years, consulting with a first-time $\mathrm{AD}$ diagnosis at a hospital dermatology clinic in Denmark during the period from 1 January 2005 to 31 December 2012. The diagnostic code for $\mathrm{AD}$ has previously been validated with a positive predictive value of $95 \%$ (98\% in children and $92 \%$ in adults, respectively) [12]. Data from each patient was used from 1 year prior to the date on which the patient is diagnosed with $\mathrm{AD}$ at the dermatology clinic through to 5 years after the time of diagnosis (i.e., up to 31 December 2017 if a patient was enrolled on 31 December 2012). Patients were followed from the date of their first AD hospital diagnosis (the "index" date, i.e., first hospital visit) occurring from 1 January 2005 to 31 December 2012. Data 1 year prior and 5 years after followup were displayed graphically and in tables. Data were extracted in 3-month increments during the observation period. Since clinical measurements of $\mathrm{AD}$ severity are lacking in large-scale administrative databases such as the ones used in this study, we performed analyses where $\mathrm{AD}$ was presumed to be severe if patients received treatment with systemic drugs used for AD. We presented comorbidity burden by use of the Charlson Comorbidity Index, which allows for a comparison of comorbidities between patients with $\mathrm{AD}$ and other disease groups on the basis of risk for mortality or resource use as previously described [20]. As this was a descriptive cohort study, we presented results as means with standard deviations (SDs) for normally distributed continuous variables and medians with interquartile ranges (IQRs) for non-normally distributed continuous variables. Count variables were presented as means with percentages and the proportions over time were displayed graphically. All analyses were performed using SAS statistical software version 9.4 (SAS Institute Inc. Cary, NC, USA) and STATA software version 13.0 (StataCorp, College Station, TX, USA).

\section{RESULTS}

In total, 8213 people with a first-time hospital dermatologist contact for $\mathrm{AD}$ were included in the study between 1 January 2005 and 31 December 2012 (3514 aged 0-9 years, 1501 aged 10-19 years, 3198 aged 20 years or older). The median (IQR) age was 15.5 (3.3-30.7), and there was a female predominance $(55.5 \%$; Table 1$)$. The differences in sex distribution were most pronounced among people aged 20-29 (30.5\% male), and 30-39 (35.2\% male), respectively. The vast majority $(88.3 \%)$ were of Danish ethnicity; however, among the youngest age group (0-9 years when first presenting at the hospital with $\mathrm{AD}), 8.6 \%$ were of Asian ethnicity, and $4.3 \%$ were of African ethnicity (Table 1), which is somewhat higher than the distribution of these ethnicities in the general population in Denmark [12].

At baseline, a history of moderately potent TCS was seen among $46.6 \%$ of children (0-9 years), whereas a history of potent or very potent TCS use was seen more frequently among older individuals. For example, 51.1\% and $25.6 \%$ of people aged 50 years or older had used potent and very potent TCS, respectively (Table 1). Overall, in the entire population (0-100 years) the prevalence of comorbidity (from the Charlson Comorbidity Index [21]) at baseline was low (all comorbidities had a prevalence of less than $2 \%$, with the exception of chronic pulmonary disease, $15.1 \%$ ). This was predominantly driven by the presence of asthma, as also seen in Table 1.

Healthcare consumption was overall highest in the year preceding and the year immediately after first AD hospital diagnosis (Table 2 and Figs. 1, 2). The median (interquartile range) annual number of visits to general practitioners at baseline was 4 (2-7) and 5 (2-8) for children and adults, respectively. Three years later, these numbers had decreased to 2 (1-4) and 3 (1-6), respectively. Among topical therapies, the most frequently used treatment modalities when presenting to the hospital were potent and moderately potent TCS (Fig. 1a). Notably, use of topical antibiotics (alone or in combination with TCS) increased in the last 3-6 months prior 


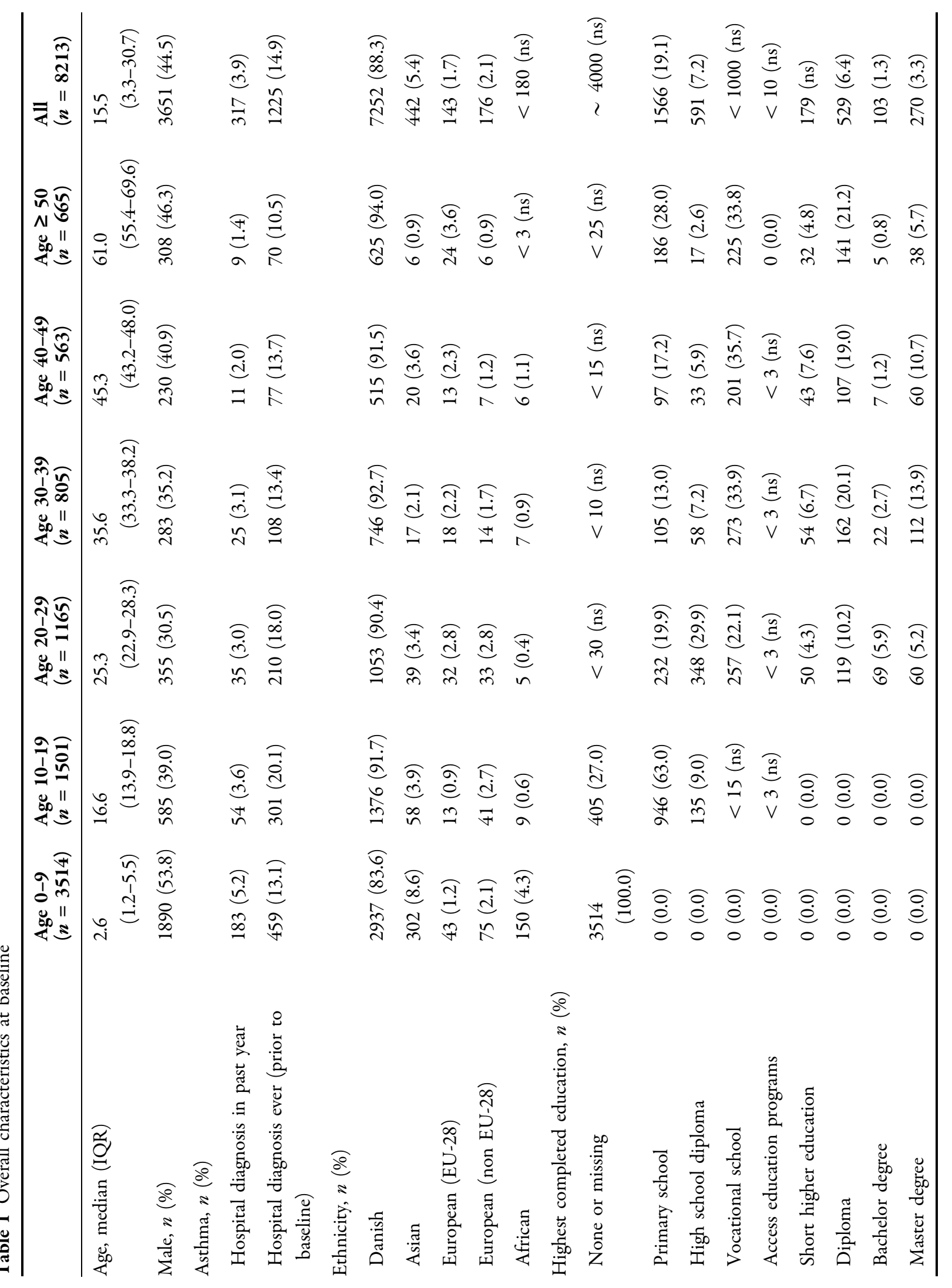




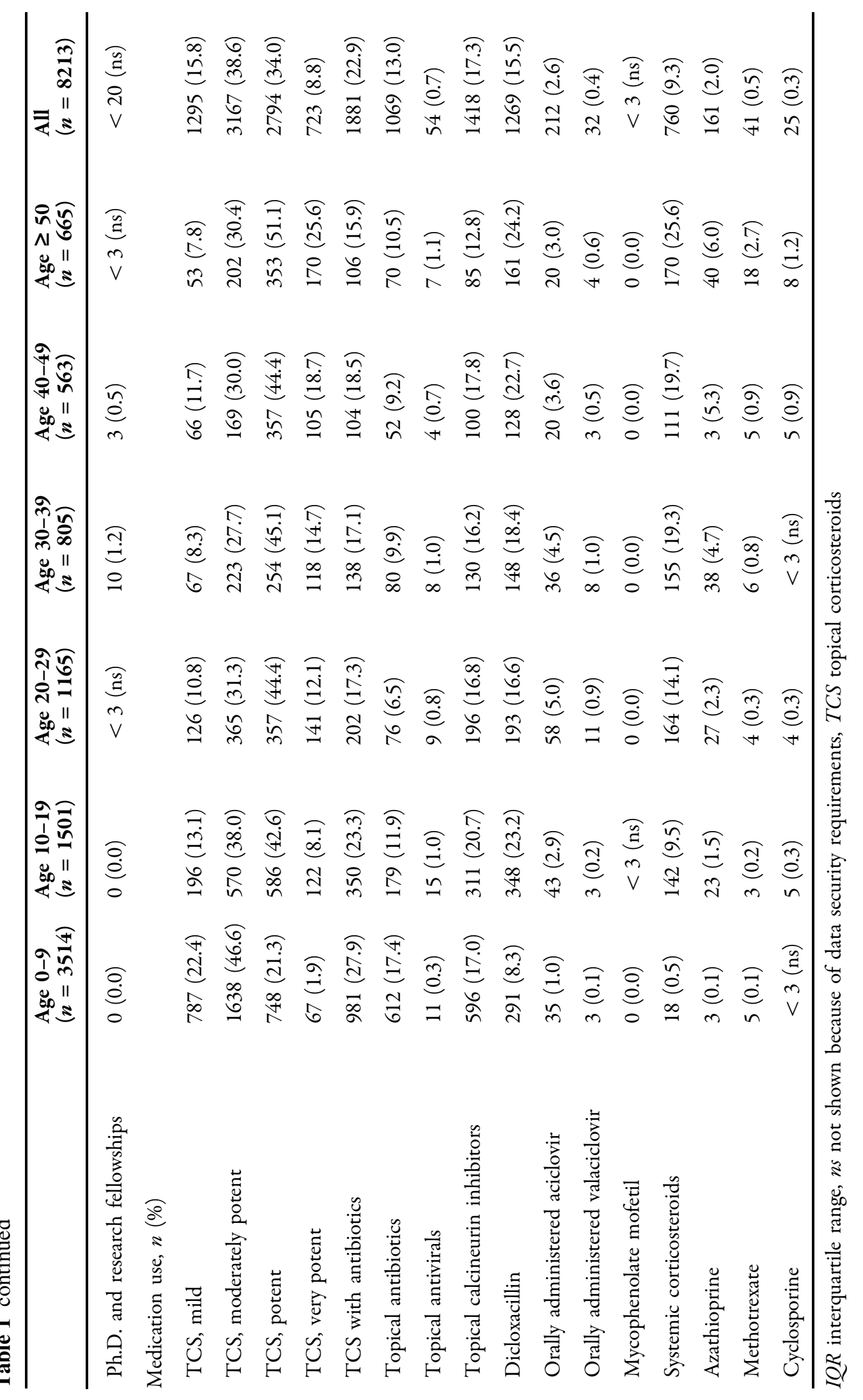


Table 2 Healthcare resource use over time

\begin{tabular}{|c|c|c|c|c|c|c|c|c|}
\hline & \multirow{2}{*}{\multicolumn{2}{|c|}{$\begin{array}{l}\text { Baseline } \\
(365 \text { to } 1 \text { day } \\
\text { before index })\end{array}$}} & \multirow{2}{*}{\multicolumn{2}{|c|}{$\begin{array}{l}1 \text { year } \\
(0-365 \text { days after } \\
\text { index })\end{array}$}} & \multirow{2}{*}{\multicolumn{2}{|c|}{$\begin{array}{l}2 \text { years } \\
(366-730 \text { days after } \\
\text { index })\end{array}$}} & \multirow{2}{*}{\multicolumn{2}{|c|}{$\begin{array}{l}3 \text { years } \\
(731-1095 \text { days } \\
\text { after index })\end{array}$}} \\
\hline & & & & & & & & \\
\hline & $\begin{array}{l}\text { Mean } \\
(\mathrm{SD})\end{array}$ & $\begin{array}{l}\text { Median } \\
\text { (IQR) }\end{array}$ & $\begin{array}{l}\text { Mean } \\
(\mathrm{SD})\end{array}$ & $\begin{array}{l}\text { Median } \\
(\mathrm{IQR})\end{array}$ & $\begin{array}{l}\text { Mean } \\
(\mathrm{SD})\end{array}$ & $\begin{array}{l}\text { Median } \\
\text { (IQR) }\end{array}$ & $\begin{array}{l}\text { Mean } \\
\text { (SD) }\end{array}$ & $\begin{array}{l}\text { Median } \\
\text { (IQR) }\end{array}$ \\
\hline \multicolumn{9}{|l|}{ Children } \\
\hline $\begin{array}{l}\text { Visit to general } \\
\text { practitioner/family } \\
\text { physician }\end{array}$ & $5.1(4.0)$ & $4(2-7)$ & $4.2(3.8)$ & $3(1-6)$ & $3.4(3.2)$ & $3(1-5)$ & $3.0(2.9)$ & $2(1-4)$ \\
\hline \multicolumn{9}{|l|}{ Visit to dermatologist, any } \\
\hline \multicolumn{9}{|c|}{ Hospital dermatology department } \\
\hline Outpatient & $0.0(0.2)$ & $0(0-0)$ & $1.1(0.6)$ & $1(1-1)$ & $0.1(0.3)$ & $0(0-0)$ & $0.1(0.3)$ & $0(0-0)$ \\
\hline Inpatient & $0.0(0.1)$ & $0(0-0)$ & $0.1(0.3)$ & $0(0-0)$ & $0.0(0.1)$ & $0(0-0)$ & $0.0(0.1)$ & $0(0-0)$ \\
\hline $\begin{array}{l}\text { Private practice } \\
\text { dermatologists }\end{array}$ & $1.5(2.5)$ & $0(0-2)$ & $0.4(1.3)$ & $0(0-0)$ & $0.3(1.3)$ & $0(0-0)$ & $0.3(1.1)$ & $0(0-0)$ \\
\hline Valaciclovir prescriptions & $0.0(0.1)$ & $0(0-0)$ & $0.0(0.1)$ & $0(0-0)$ & $0.0(0.1)$ & $0(0-0)$ & $0.0(0.1)$ & $0(0-0)$ \\
\hline Aciclovir prescriptions & $0.2(0.3)$ & $0(0-0)$ & $0.0(0.4)$ & $0(0-0)$ & $0.0(0.3)$ & $0(0-0)$ & $0.0(0.3)$ & $0(0-0)$ \\
\hline Dicloxacillin prescriptions & $0.2(0.6)$ & $0(0-0)$ & $0.1(0.5)$ & $0(0-0)$ & $0.1(0.3)$ & $0(0-0)$ & $0.0(0.3)$ & $0(0-0)$ \\
\hline $\begin{array}{l}\text { Potassium permanganate } \\
\text { baths }\end{array}$ & $0.1(0.8)$ & $0(0-0)$ & $0.0(0.5)$ & $0(0-0)$ & $0.0(0.2)$ & $0(0-0)$ & $0.0(0.0)$ & $0(0-0)$ \\
\hline \multicolumn{9}{|l|}{ Adults } \\
\hline $\begin{array}{l}\text { Visit to general } \\
\text { practitioner/family } \\
\text { physician }\end{array}$ & $5.6(4.6)$ & $5(2-8)$ & $5.0(4.9)$ & $4(2-7)$ & $4.7(4.6)$ & $3(1-6)$ & $4.5(4.6)$ & $3(1-6)$ \\
\hline \multicolumn{9}{|l|}{ Visit to dermatologist } \\
\hline \multicolumn{9}{|c|}{ Hospital dermatology department } \\
\hline Outpatient & $0.1(0.3)$ & $0(0-0)$ & $1.1(0.5)$ & $1(1-1)$ & $0.1(0.4)$ & $0(0-0)$ & $0.1(0.3)$ & $0(0-0)$ \\
\hline Inpatient & $0.0(0.2)$ & $0(0-0)$ & $0.1(0.4)$ & $0(0-0)$ & $0.0(0.2)$ & $0(0-0)$ & $0.0(0.4)$ & $0(0-0)$ \\
\hline $\begin{array}{l}\text { Private practice } \\
\text { dermatologists }\end{array}$ & $2.8(5.1)$ & $1(0-4)$ & $0.8(2.7)$ & $0(0-0)$ & $0.6(2.5)$ & $0(0-0)$ & $0.6(2.5)$ & $0(0-0)$ \\
\hline Valaciclovir prescriptions & $0.0(0.4)$ & $0(0-0)$ & $0.0(0.6)$ & $0(0-0)$ & $0.0(0.5)$ & $0(0-0)$ & $0.0(0.4)$ & $0(0-0)$ \\
\hline Aciclovir prescriptions & $0.1(0.6)$ & $0(0-0)$ & $0.1(0.7)$ & $0(0-0)$ & $0.1(0.6)$ & $0(0-0)$ & $0.1(0.8)$ & $0(0-0)$ \\
\hline Dicloxacillin prescriptions & $0.4(0.9)$ & $0(0-0)$ & $0.3(1.0)$ & $0(0-0)$ & $0.2(0.6)$ & $0(0-0)$ & $0.1(0.6)$ & $0(0-0)$ \\
\hline
\end{tabular}


Table 2 continued

\begin{tabular}{|c|c|c|c|c|c|c|c|c|}
\hline & \multirow{2}{*}{\multicolumn{2}{|c|}{$\begin{array}{l}\text { Baseline } \\
\text { (365 to } 1 \text { day } \\
\text { before index })\end{array}$}} & \multirow{2}{*}{\multicolumn{2}{|c|}{$\begin{array}{l}\text { year } \\
(0-365 \text { days after } \\
\text { index })\end{array}$}} & \multirow{2}{*}{\multicolumn{2}{|c|}{$\begin{array}{l}2 \text { years } \\
\text { (366-730 days after } \\
\text { index) }\end{array}$}} & \multirow{2}{*}{\multicolumn{2}{|c|}{$\begin{array}{l}3 \text { years } \\
(731-1095 \text { days } \\
\text { after index })\end{array}$}} \\
\hline & & & & & & & & \\
\hline & $\begin{array}{l}\text { Mean } \\
\text { (SD) }\end{array}$ & $\begin{array}{l}\text { Median } \\
(\mathrm{IQR})\end{array}$ & $\begin{array}{l}\text { Mean } \\
\text { (SD) }\end{array}$ & $\begin{array}{l}\text { Median } \\
\text { (IQR) }\end{array}$ & $\begin{array}{l}\text { Mean } \\
\text { (SD) }\end{array}$ & $\begin{array}{l}\text { Median } \\
(\mathrm{IQR})\end{array}$ & $\begin{array}{l}\text { Mean } \\
\text { (SD) }\end{array}$ & $\begin{array}{l}\text { Median } \\
\text { (IQR) }\end{array}$ \\
\hline $\begin{array}{l}\text { Potassium permanganate } \\
\text { baths }\end{array}$ & $0.1(1.3)$ & $0(0-0)$ & $0.0(0.4)$ & $0(0-0)$ & $0.0(0.2)$ & $0(0-0)$ & $0.0(0.4)$ & $0(0-0)$ \\
\hline
\end{tabular}

Visits to general practitioners shown here, may not necessarily be due to AD

$S D$ standard deviation, $I Q R$ interquartile range

to the hospital visit, and decreased thereafter (Fig. 1a), and use of systemic corticosteroids increased dramatically in the months preceding the initial hospital visit, after which the use decreased considerably (Fig. 1b). Use of systemic dicloxacillin (i.e., the preferred oral antibiotic for treatment Staphylococcus aureus in Denmark) increased dramatically in the last months prior to first hospital visit (Fig. 2a) whereas no major change was observed for systemic antiviral therapies (Fig. 2a). Use of other systemic treatments, in particular azathioprine and phototherapy, increased noticeably around the time of first hospital visit (Fig. 1b) albeit the use of these drugs was generally very low.

Most frequently, patients received monotherapy with potent or moderately potent TCS (Fig. 2b), and when stratified by disease severity, patients classified as having mild disease (i.e., those never treated with systemic therapies) most frequently used moderately potent TCS followed by potent TCS (Fig. 2c), whereas patients classified as having severe disease (i.e., those at some point receiving systemic treatment) most frequently used potent TCS followed by moderately potent TCS (Fig. 2d). Data presented in 3-month increments are available from Table 3.

\section{DISCUSSION}

In this longitudinal cohort study of patients with AD in Denmark, the most frequently prescribed systemic therapies in the months immediately prior to first hospital dermatologist visit were systemic corticosteroids and dicloxacillin. Approximately one-third of patients were prescribed a potent or moderately potent TCS when referred for hospital-based treatment, and very few patients were treated with systemic therapies. These findings suggest either a considerable undertreatment among patients with AD in Denmark or that patients are mainly referred for treatment of a single severe flare that quickly resolved. Regardless, our findings highlight considerable differences in treatment patterns between general practitioners and private practice dermatologists, compared with hospital-based dermatologists.

The dramatic increase in use of topical or systemic antibiotics and systemic corticosteroids in the last 3-6 months prior to the first hospital referral could suggest that many such hospital referrals are driven in part by uncontrolled disease with frequent skin infections, requiring more intensified or specialized treatment and proper education in how to manage their AD. Notably, however, the spike in use of systemic corticosteroids, followed by a steep decline in such prescriptions after referral, shows a clear divergence from national guidelines which do not recommend use of systemic 
(a)

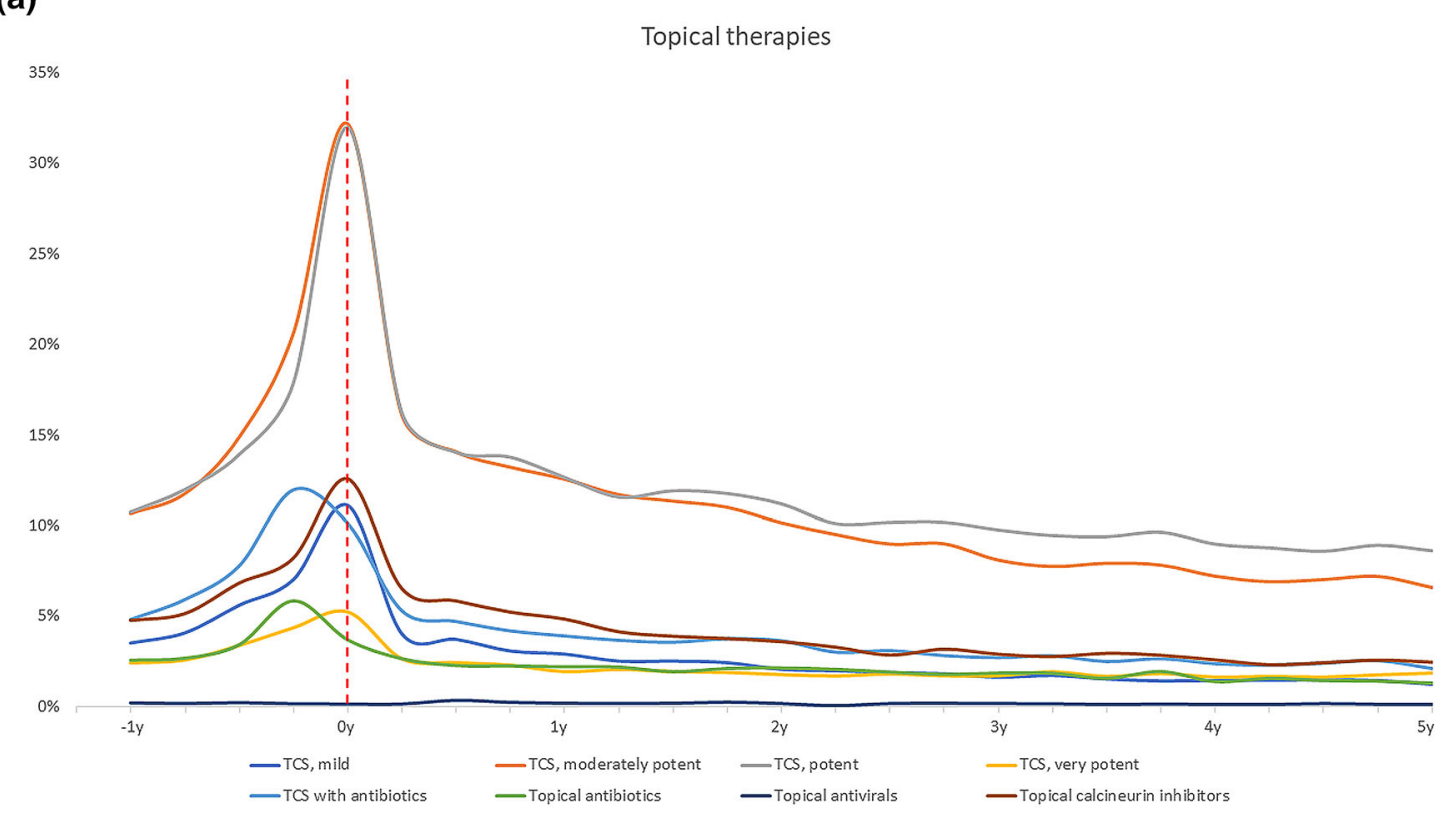

(b)

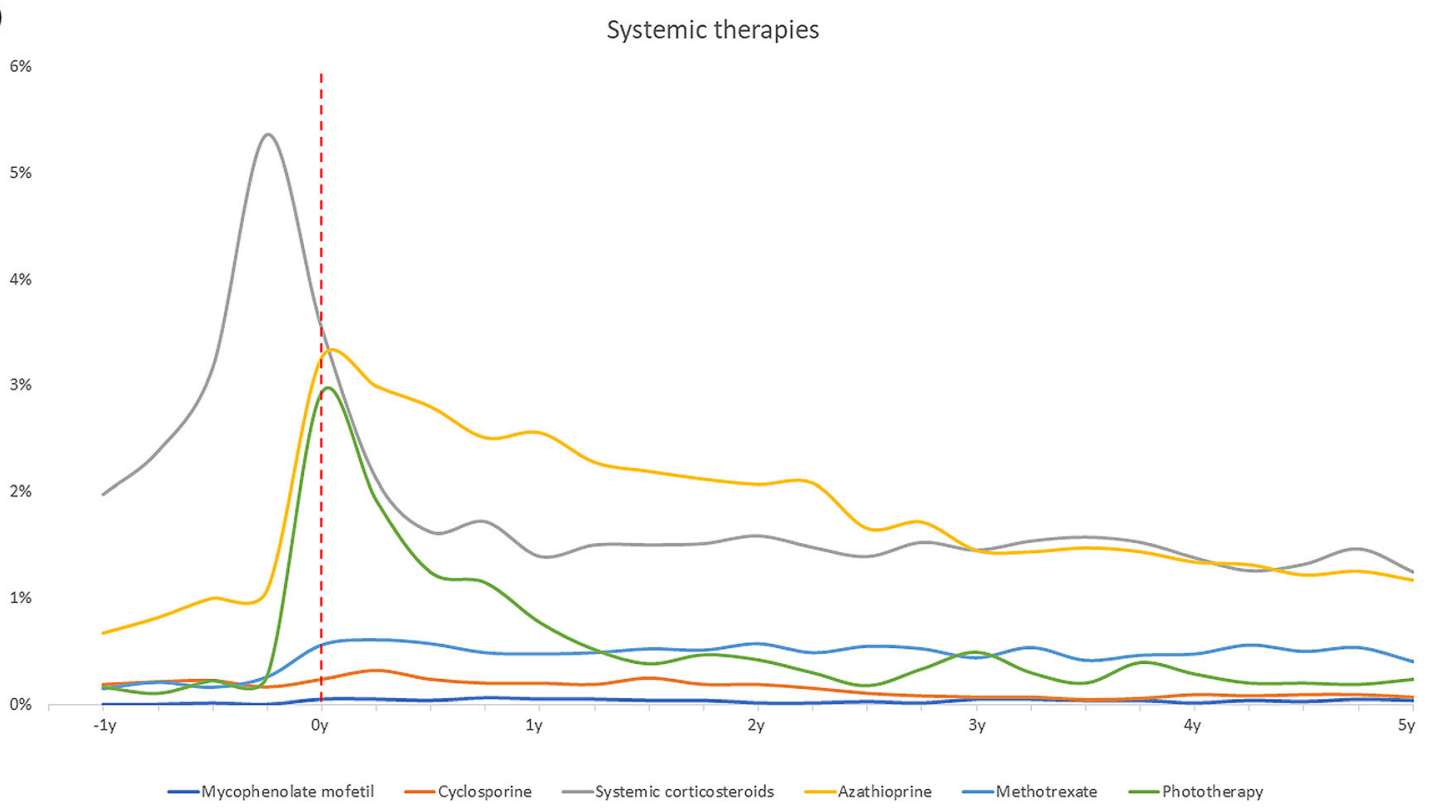

Fig. 1 Use of topical and systemic therapies over time relative to first AD visit. a Topical therapies, $\mathbf{b}$ systemic therapies

corticosteroids as a standard treatment of $\mathrm{AD}$, but recommend that this is reserved for special cases of severe uncontrollable flares [14]. Again, this could also represent a need for further educational efforts of general practitioners and private practice dermatologists to ensure that novel treatment guidelines and recommendations are correctly applied. The overall very low prevalence of systemic therapy in our study is supported by previous studies from Denmark, where only $7 \%$ of patients with severe $\mathrm{AD}$ received systemic therapy [22, 23]. Notably, the AD diagnosis has been validated in children and adults with very high positive 


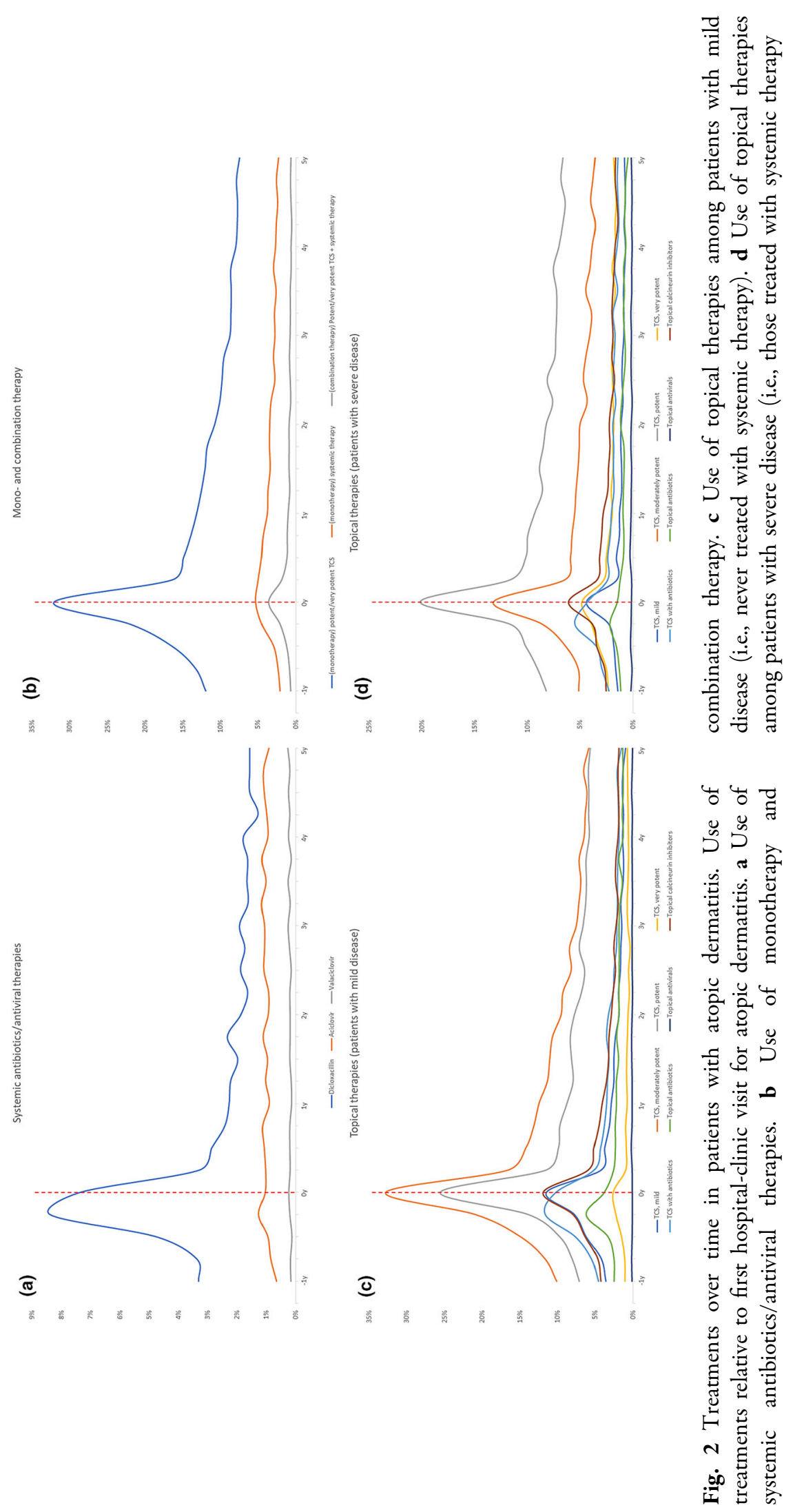




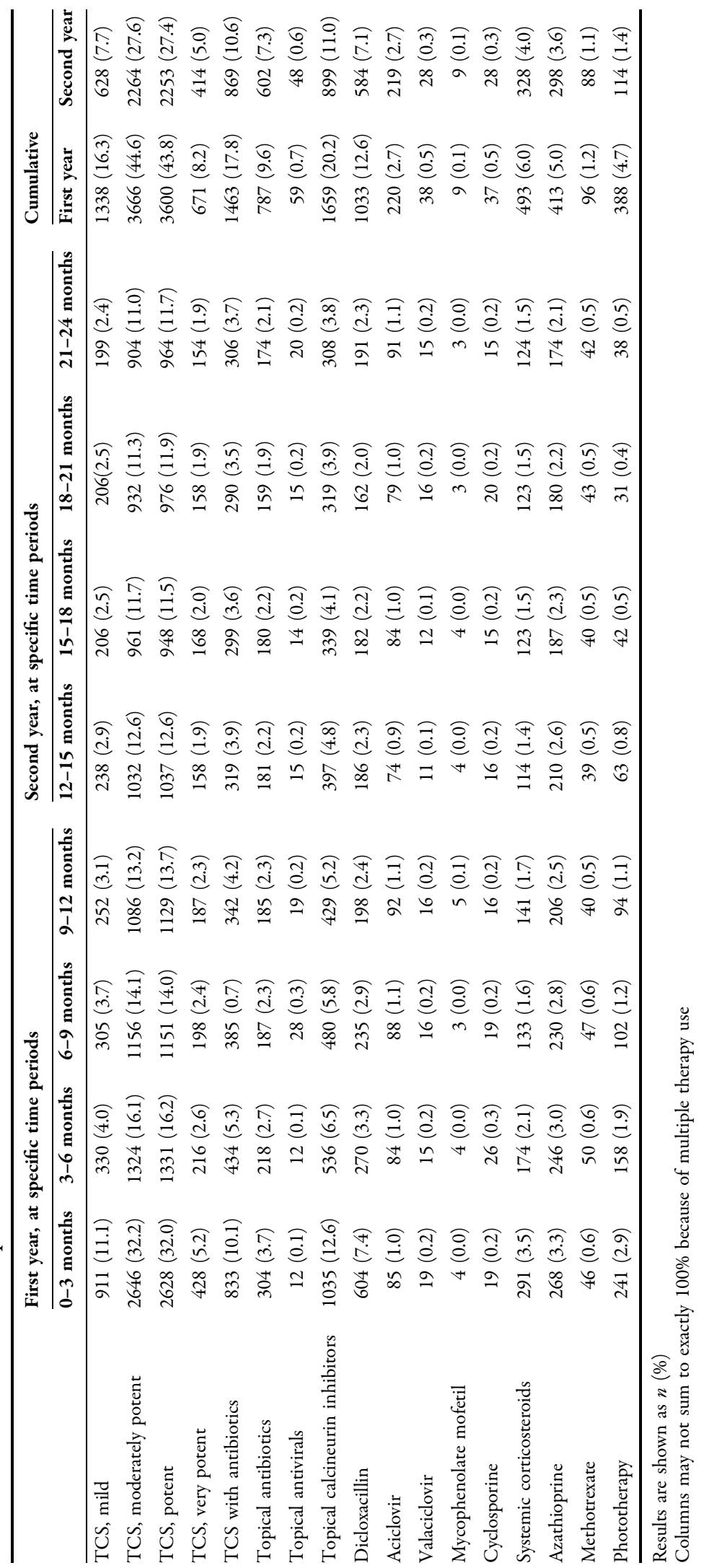


predictive values in the Danish registries, thus ensuring that patients indeed had $\mathrm{AD}$ at the time of their referral [12]. A novel finding, however, is the somewhat low use of potent TCS, which could either be a sign of general undertreatment across therapies or due to steroid-phobia among patients [24]. Nonetheless, the low use of established $\mathrm{AD}$ therapies is in stark contrast to the high symptom burden and need for disease resolution that is reported among patients with $\mathrm{AD}[6,22]$. Notably, the Danish healthcare system provides partial reimbursement of pharmacy-filled prescriptions, including those for topical therapies, and systemic treatments given from hospital clinics (e.g., dupilumab and methotrexate) are provided without the need for co-payment, which therefore should enable a greater access to appropriate therapies to better manage patients' AD. Taken together, these findings suggest that further efforts are needed to heighten the adherence to evidence- and consensus-based treatment guidelines and defined treatment targets, and to provide more optimal care for patients with $\mathrm{AD}$.

Certain limitations apply to the interpretation of the present findings. The study inclusion period was between 2005 and 2012, i.e., before dupilumab was available for treatment of $\mathrm{AD}$. With the advent and introduction of more potent therapies and the subsequent increased disease awareness, it is possible that treatment patterns will change. However, very recent data still suggest that patients with AD in Denmark are markedly undertreated [22]. In the present study we lacked clinical information on disease severity; however, even among patients treated with systemics, i.e., arguably the most severe patients, use of either mono- or combination therapy was very limited, thus highlighting the robustness of our initial findings. Moreover, we lacked data on use of emollients, as such information is not recorded in our data sources. The study was limited to patients that were eventually referred for hospital-based dermatology treatment, and whether the findings also applies to other patient segments such as those only ever seen by private practice dermatologists or general practitioners remains unclear. Lastly, since these data were based on patients seen in the Danish healthcare system, extrapolation to other countries should be done with caution.

In conclusion, we found that a proportion of patients with $\mathrm{AD}$ were treated with antibiotics (topical or systemic) and systemic corticosteroids prior to being referred for hospital-based dermatologist treatment. Generally, low proportions of patients received systemic or even potent topical therapy, suggesting that many patients may still be undertreated or that many patients only experience brief flares that quickly resolve. These findings highlight considerable differences in treatment patterns between general practitioners and private practice dermatologists, compared with hospital-based dermatologists, and emphasize the need for better adherence to evidence-based treatment guidelines.

\section{ACKNOWLEDGEMENTS}

Funding. The study and the journal's rapid service fee was supported by Eli Lilly and Company.

Authorship. All named authors meet the International Committee of Medical Journal Editors (ICMJE) criteria for authorship for this article, take responsibility for the integrity of the work as a whole, and have given their approval for this version to be published.

Disclosures. Dr. Alexander Egeberg has received research funding from Pfizer, Eli Lilly, the Danish National Psoriasis Foundation, and the Kgl Hofbundtmager Aage Bang Foundation, and honoraria as consultant and/or speaker from AbbVie, Almirall, Leo Pharma, Samsung Bioepis Co., Ltd., Pfizer, UCB, Eli Lilly and Company, Novartis, Galderma, Dermavant, Bristol-Myers Squibb, and Janssen Pharmaceuticals. Dr. Jacob Thyssen has attended advisory boards for Eli Lilly \& Co, Pfizer, Abbvie, LEO Pharma, and Sanofi-Genzyme; received speaker honorarium from LEO Pharma, Regeneron, Abbvie and Sanofi-Genzyme and been an investigator for LEO Pharma, Eli Lilly \& Co, 
Abbvie, Pfizer, and Sanofi-Genzyme. Dr. Jashin $\mathrm{Wu}$ is or has been an investigator, consultant, or speaker for AbbVie, Almirall, Amgen, Boehringer Ingelheim, Bristol-Myers Squibb, Celgene, Dermavant, Dermira, Dr. Reddy's Laboratories, Eli Lilly, Janssen, LEO Pharma, Novartis, Regeneron, Sanofi Genzyme, Sun Pharmaceutical, UCB, Valeant Pharmaceuticals North America LLC. Drs. Evangeline Pierce and Jorge Terres are currently employed by Eli Lilly and Company.

Compliance with Ethics Guidelines. Approval from an ethics committee is not required for register studies in Denmark (Danish law: Lov om videnskabsetisk behandling af sundhedsvidenskabelige forskningsprojekter, $§ 14$, stk. 2).

Data Availability. The datasets generated during and/or analyzed during the current study are not publicly available due to Danish law. The repository can only be accessed by authorized researchers.

Open Access. This article is licensed under a Creative Commons Attribution-NonCommercial 4.0 International License, which permits any non-commercial use, sharing, adaptation, distribution and reproduction in any medium or format, as long as you give appropriate credit to the original author(s) and the source, provide a link to the Creative Commons licence, and indicate if changes were made. The images or other third party material in this article are included in the article's Creative Commons licence, unless indicated otherwise in a credit line to the material. If material is not included in the article's Creative Commons licence and your intended use is not permitted by statutory regulation or exceeds the permitted use, you will need to obtain permission directly from the copyright holder. To view a copy of this licence, visit http://creativecommons.org/licenses/by$\mathrm{nc} / 4.0 /$.

\section{REFERENCES}

1. Wallach D, Taieb A. Atopic dermatitis/atopic eczema. Chem Immunol Allergy. 2014;100:81-96.

2. Odhiambo JA, Williams HC, Clayton TO, et al. Global variations in prevalence of eczema symptoms in children from ISAAC Phase Three. J Allergy Clin Immunol. 2009;124(1251-8):e23.

3. Zuberbier T, Lotvall J, Simoens S, et al. Economic burden of inadequate management of allergic diseases in the European Union: a GA(2) LEN review. Allergy. 2014;69:1275-9.

4. Capucci S, Hahn-Pedersen J, Vilsboll A, et al. Systematic reviews of the impact of atopic dermatitis and chronic hand eczema on quality of life compared with other chronic diseases. Dermatitis. 2020;31:178-84.

5. Deckers IA, McLean S, Linssen S, et al. Investigating international time trends in the incidence and prevalence of atopic eczema 1990-2010: a systematic review of epidemiological studies. PLoS One. 2012;7:e39803.

6. Egeberg A, Griffiths CEM, Williams HC, et al. Clinical characteristics, symptoms and burden of psoriasis and atopic dermatitis in adults. Br J Dermatol. 2019;183:128-38.

7. Ren Z, Silverberg JI. Association of atopic dermatitis with bacterial, fungal, viral, and sexually transmitted skin infections. Dermatitis. 2020;31:157-64.

8. Andersen YMF, Egeberg A, Gislason GH, et al. Burden of respiratory comorbidities in patients with atopic dermatitis and psoriasis. $\mathrm{Br} \mathrm{J}$ Dermatol. 2017;177:e145-6.

9. Ballardini N, Kull I, Soderhall C, et al. Eczema severity in preadolescent children and its relation to sex, filaggrin mutations, asthma, rhinitis, aggravating factors and topical treatment: a report from the BAMSE birth cohort. Br J Dermatol. 2013;168: 588-94.

10. Weidinger S, Novak N. Atopic dermatitis. Lancet. 2016;387:1109-22.

11. Egeberg A, Andersen YMF, Gislason GH, et al. Differential disease burden and treatment patterns among adults with psoriasis and atopic dermatitis seen in hospital vs private clinics. J Eur Acad Dermatol Venereol. 2018;32:e23-5.

12. Andersen YMF, Egeberg A, Skov L, et al. Demographics, health care utilization, and drug use in children and adults with atopic dermatitis in 
Denmark: a population-based cross-sectional study. J Eur Acad Dermatol Venereol. 2019;33:1133-42.

13. Flohr C, Irvine AD. Systemic therapies for severe atopic dermatitis in children and adults. J Allergy Clin Immunol. 2013;132:774-e6.

14. Udredning og behandling af patienter med atopisk dermatitis (AD). Dansk Dermatologisk Selskab, Version 1.1(2) draft. In, Vol. 2020. https://dds.nu/ wp-content/uploads/2019/04/22-03-20-ADguideline-final-002.pdf.

15. Schmidt M, Pedersen L, Sorensen HT. The Danish Civil Registration System as a tool in epidemiology. Eur J Epidemiol. 2014;29:541-9.

16. Mason K, Thygesen LC, Stenager E, et al. Evaluating the use and limitations of the Danish National Patient Register in register-based research using an example of multiple sclerosis. Acta Neurol Scand. 2012;125:213-7.

17. Schmidt M, Schmidt SA, Sandegaard JL, et al. The Danish National Patient Registry: a review of content, data quality, and research potential. Clin Epidemiol. 2015;7:449-90.

18. Andersen JS, Olivarius Nde F, Krasnik A. The Danish National Health Service Register. Scand J Public Health. 2011;39:34-7.
19. Pottegard A, Schmidt SAJ, Wallach-Kildemoes H, et al. Data resource profile: the Danish National Prescription Registry. Int J Epidemiol. 2017;46:798f.

20. Thyssen JP, Skov L, Hamann CR, et al. Assessment of major comorbidities in adults with atopic dermatitis using the Charlson comorbidity index. J Am Acad Dermatol. 2017;76:1088-92.e1.

21. Charlson M, Szatrowski TP, Peterson J, et al. Validation of a combined comorbidity index. J Clin Epidemiol. 1994;47:1245-51.

22. Egeberg A, Thyssen JP. Factors associated with patient-reported importance of skin clearance among adults with psoriasis and atopic dermatitis. J Am Acad Dermatol. 2019;81:943-9.

23. Pascal C, Maucort-Boulch D, Gilibert S, et al. Therapeutic management of adults with atopic dermatitis: comparison with psoriasis and chronic urticaria. J Eur Acad Dermatol Venereol. 2020;13: 100222.

24. Andersen YMF, Augustin M, Petersen J, et al. Characteristics and prevalence of plaque psoriasis in patients with palmoplantar pustulosis. Br J Dermatol. 2019;181:976-82. 